\title{
ПРИРООНИЧO-ГЕОГРАФМИНI DOCIIOKEHHG
}

\author{
УДК 551.482; 556.02

\section{Н.И. Коронкевич, Е.А. Барабанова, С.В. Долгов, И.С.Зайщева ВОДНЫЕ ПРОБЛЕМЫ НАЧАЛА ХХІ ВЕКА}

\begin{abstract}
Н.И. Коронкевич, Е.А. Барабанова, С.В. Долгов, И.С.Зайцева ВОДНЫЕ ПРОБЛЕМЫ НАЧАЛА ХХІ ВЕКА

Институт географии Российской академии наук, Москва

Рассмотрены водные проблемы, связанные с наводнениями, маловодьями, загрязнением рек и водоемов. Показано, что в начале XXI века многие из них обострились из-за климатических изменений, а также нерациональной хозяйственной деятельности. Это положение иллюстрируется на примере мира в целом и России. Названы наиболее радикальные мероприятия, направленные на снижение негативных последствий неблагоприятных гидрологических явлений.
\end{abstract}

Ключевые слова: водные проблемы; наводнения; маловодья; загрязнение рек и водоемов; XXI век; мир; Россия.

\section{N. Koronkiewicz, Ye. Barabanova, S. Dolgov, I. Zaytseva WATER PROBLEMS IN THE EARLY XXI CENTURY}

Institute of Geography of Russian Academy of Sciences, Moscow

Water issues related to floods, water shortage, pollution of rivers and reservoirs have been reviewed. It is shown that in the beginning of XXI century, many of them have exacerbated due to climate change, and unsustainable economic activities. This statement is illustrated using the example of the world in general, and Russia. The most radical measures aimed at reduction of unfavorable hydrological phenomena negative effects have been identified.

Keywords: water floods; water shortages; pollution of rivers and reservoirs; XXI century world; Russia.

Основные водные проблемы начала XXI в. не новы - это наводнения, маловодья, загрязнение рек и водоемов. Но в XXI в. они, как будет показано ниже, обострились в большинстве регионов мира.

\section{Наводнения и маловодья}

В основном они обусловлены экстремальным состоянием природно-климатических ситуаций. Но и роль антропогенных факторов во многих случаях весьма велика. С 1985 г. детальный учет всех н а в одне н и й в мире ведет Дартмутская обсерватория в штате Нью-Джерси в США. Ее данные за 1985-2009 гг. обобщены А.А. Таратуниным [7]. На основании этих обобщений нами было выполнено сопоставление числа наводнений за 1985-1997 и 1998-2009 гг. Рассмотрены наводнения трех классов - сравнительно небольшие (с вероятностью появления 1 раз в 10-20 лет), средние и самые высокие, как правило, катастрофические (1 раз в 100 лет и реже). На рис. 1-2 представлены три линии, соответствующие среднему показателю за 1985-2009гг., 1985-1997 гг. и 1998-2009 гг. Даже имея в виду несколько отличающиеся уровни достоверности статистики за эти периоды, не вызы-

Работа выполнена при финансовой поддержке Российского фонда фундаментальных исследований по проекту № 12-05-00838 вает сомнения нарастание числа наводнений всех классов (рис. 1) и самых опасных наводнений в последние годы (рис. 2). Так, общее число наводнений возросло в среднем почти в 2 раза. Практически каждые два дня в начале XXI в. в мире случается наводнение и каждые 40 дней - катастрофическое. Аналогичная динамика прослеживается по таким показателям наводнений, как площадь ежегодно затопляемых земель (увеличение в 1,8 раза - до 18,5 млн км²), число эвакуируемых (с 19,5 до 33 млн чел.), число погибших ( с 17,2 до 30,7 тыс. чел.), общий ущерб (с 24,9 до 42,5 млрд долл.). С 1985 г. по 2009 г. общий ущерб от наводнений составляет по весьма осторожной оценке более 830 млрд долл. США, в т.ч. за 1998-2009 гг. почти 510 млрд долл.

Практически во всех странах, подверженных наводнениям, ведется их изучение. Большое внимание им уделяется и в России [2, 6, 8 и др.]. В начале XXI века особенно активизировались наводнения в трех регионах - на Северном Кавказе, в бассейне р. Лены (Якутия) и на Дальнем Востоке (таблица 1).

Остановимся несколько подробнее на наводнении в г. Крымске (бассейн р. Кубани) [4] и случившемся совсем недавно наводнении на Дальнем Востоке. Было показано, что интенсивные осадки, вызвавшие экстремальные по величине расходы воды (более $\left.1000 \mathrm{~m}^{3} / \mathrm{c}\right)$ в р. Адагум, стали главной 


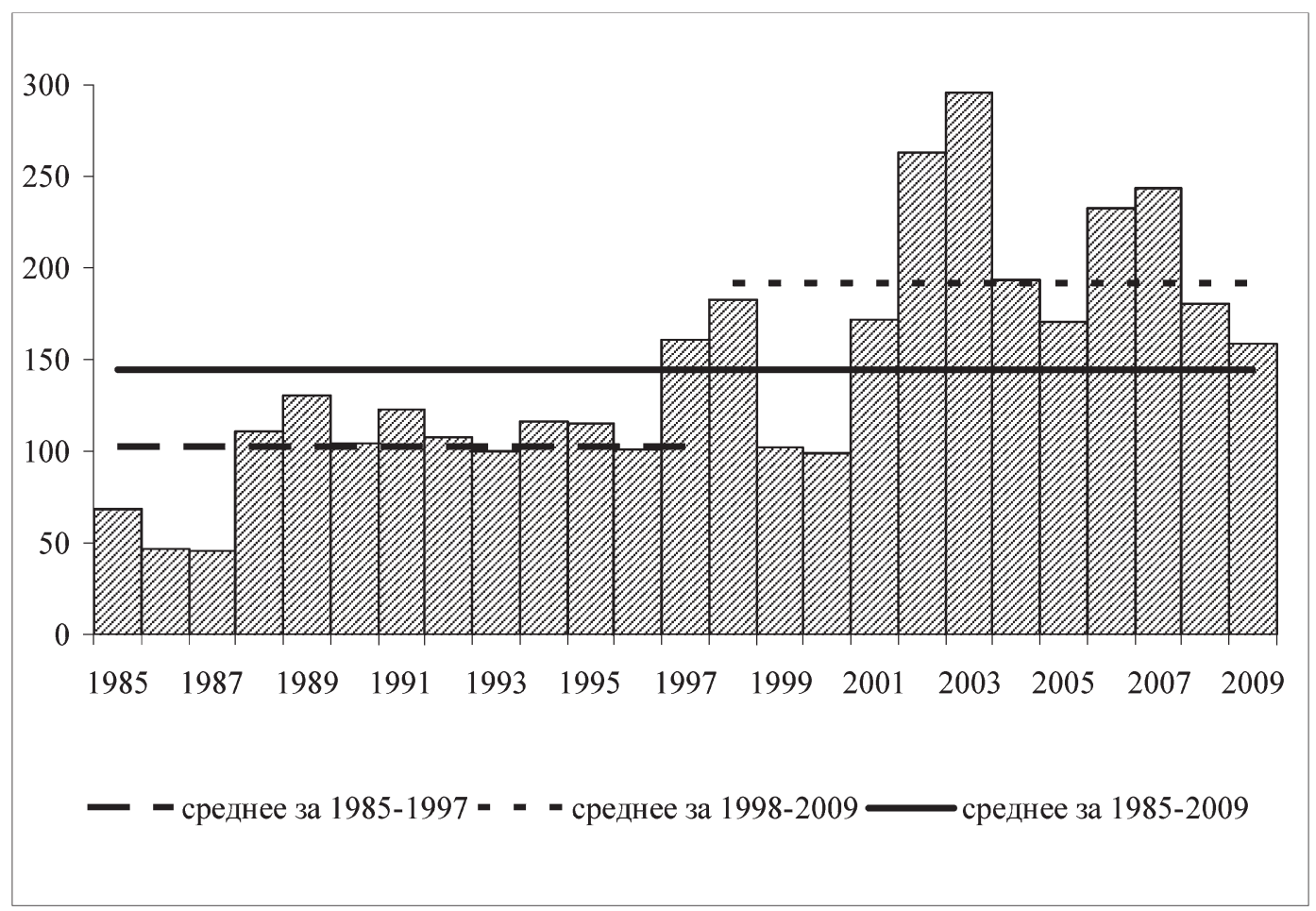

Рисунок 1. Динамика числа наводнений всех классов в мире

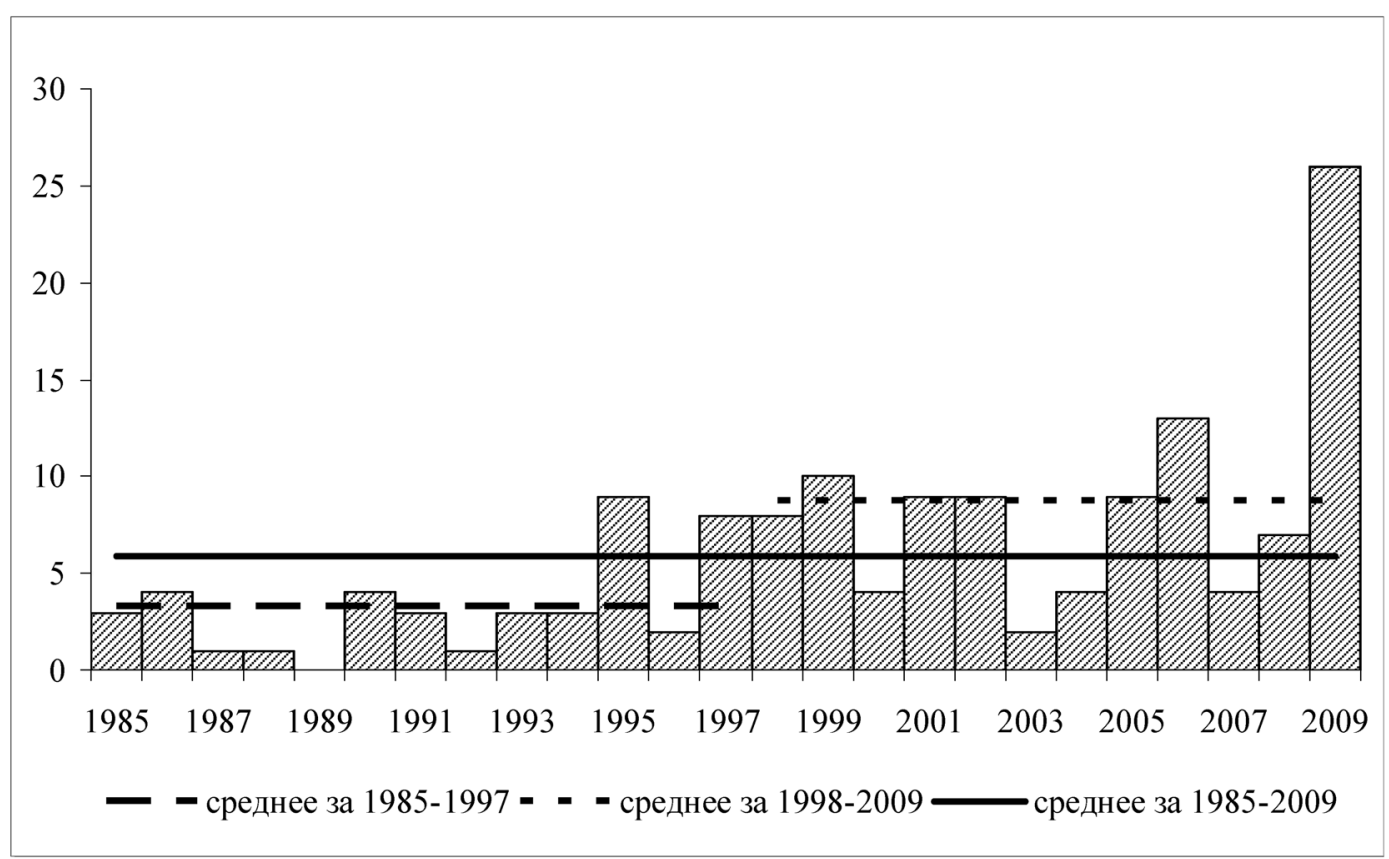

Рисунок 2. Динамика числа наводнений 3 класса (повторяемостью 1 раз в 100 лет и реже) в мире

Таблица 1. Наиболее известные наводнения в России в XXI веке

\begin{tabular}{|l|l|}
\hline \multicolumn{1}{|c|}{ Регион } & \multicolumn{1}{|c|}{ Наводнения } \\
\hline \multirow{3}{*}{ Северный Кавказ } & Бассейн Кубани, лето 2002 г. (в результате дождевых осадков) \\
\cline { 2 - 3 } & р. Геналдон, сентябрь 2002 г. (в результате подвижки ледника Колка) \\
\cline { 2 - 3 } & р.Адагум, июль 2012 г., г. Крымск (из-за обильных дождей) \\
\hline Якутия & Бассейн Лены, гг. Ленск, Якутск, май 2001 г. (из-за заторов льда) \\
\hline Дальний Восток & $\begin{array}{l}\text { Бассейн Амура, август-сентябрь 2013 г. (из-за обильных и } \\
\text { продолжительных дождей) }\end{array}$ \\
\hline
\end{tabular}




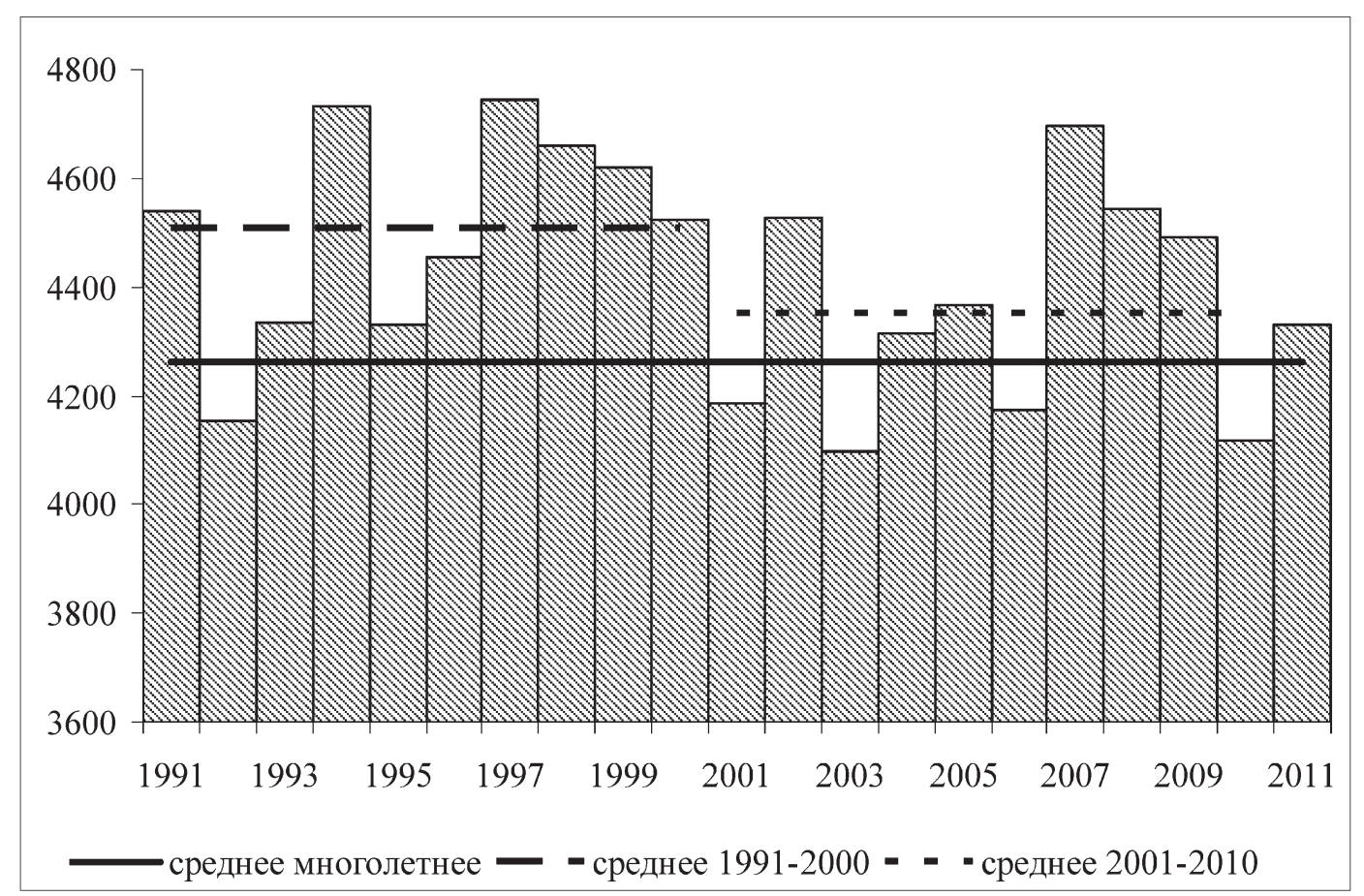

Рисунок 3. Годовой сток России, км³

причиной этого наводнения. Уровень воды в реке поднялся на 7-9 м. Число человеческих жертв достигло 171 человека. Высота подъема уровня воды, число жертв и ущерб могли бы быть меньше, если бы русло реки и ее притоков не были захламлены, а прибрежная полоса, вопреки требованиям безопасности, не была застроена. Кроме того, были просчеты в оповещении населения и организации спасения людей во время ночного наводнения.

Экстремальное наводнение в бассейне Амура вызвано рекордными по продолжительности муссонными дождями, охватившими практически весь бассейн как на территории РФ, так и Китая. Одно из объяснений обильного и длительного выпадения осадков заключается в том, что к северу от бассейна Амура сформировалась устойчивая область высокого давления, под влиянием которой в бассейн Амура на длительный срок переместились влагонесущие воздушные потоки, которые обычно имели направление с юго-востока на северо-запад.

Сыграло свою роль и стеснение русла реки различными постройками. Высокий подъем воды и затопление территории связаны также с многолетней вырубкой лесов, несовершенством гидрометеорологических прогнозов в условиях сокращения числа метео- и гидропостов, неудовлетворительным состоянием многих дамб.

Зейский и Бурейский гидроузлы на притоках Амура Зее и Бурее, многочисленные, хотя и небольшие, водохранилища на территории Китая сыграли положительную роль в начальной стадии формирования паводка, но ко времени наступления его пика оказались заполненными и вынуждены были сбра- сывать накопившуюся воду, чтобы избежать разрушения. В итоге высота подъема воды у гг. Хабаровск и Комсомольск-на-Амуре превысила 8 и 9 м, были затоплены огромные территории.

Уже из этих примеров видно, что роль деятельности человека в формировании экстремальных расходов воды, особенно размера их последствий весьма велика. Наиболее яркими проявлениями этой роли являются прорывы недостаточно надежных гидроузлов, особенно небольших, часто создаваемых без должного гидрологического обоснования.

Наводнения связаны, хотя и не очень тесно, с общей водностью рек и водоемов. В этой связи следует отметить имеющее место увеличение стока рек земного шара, в значительной мере за счет ускоренного таяния ледников.

В России в целом также происходит увеличение стока, хотя и замедлившееся в последние годы (рис. 3). Для отдельных рек ситуация может существенно отличаться. Например, если сток в бассейне Волги во многом повторяет общероссийскую картину, то Дон имеет выраженную тенденцию к уменьшению стока.

Очень важно отметить происходящие изменения в сезонной структуре стока, заключающиеся в том, что снижается объем стока весеннего половодья, а возрастает повторяемость и величина летних и, особенно, зимних паводков. Это хорошо показано в монографии [1], согласно которой зимний сток на многих реках европейской части России возрос на десятки процентов. 


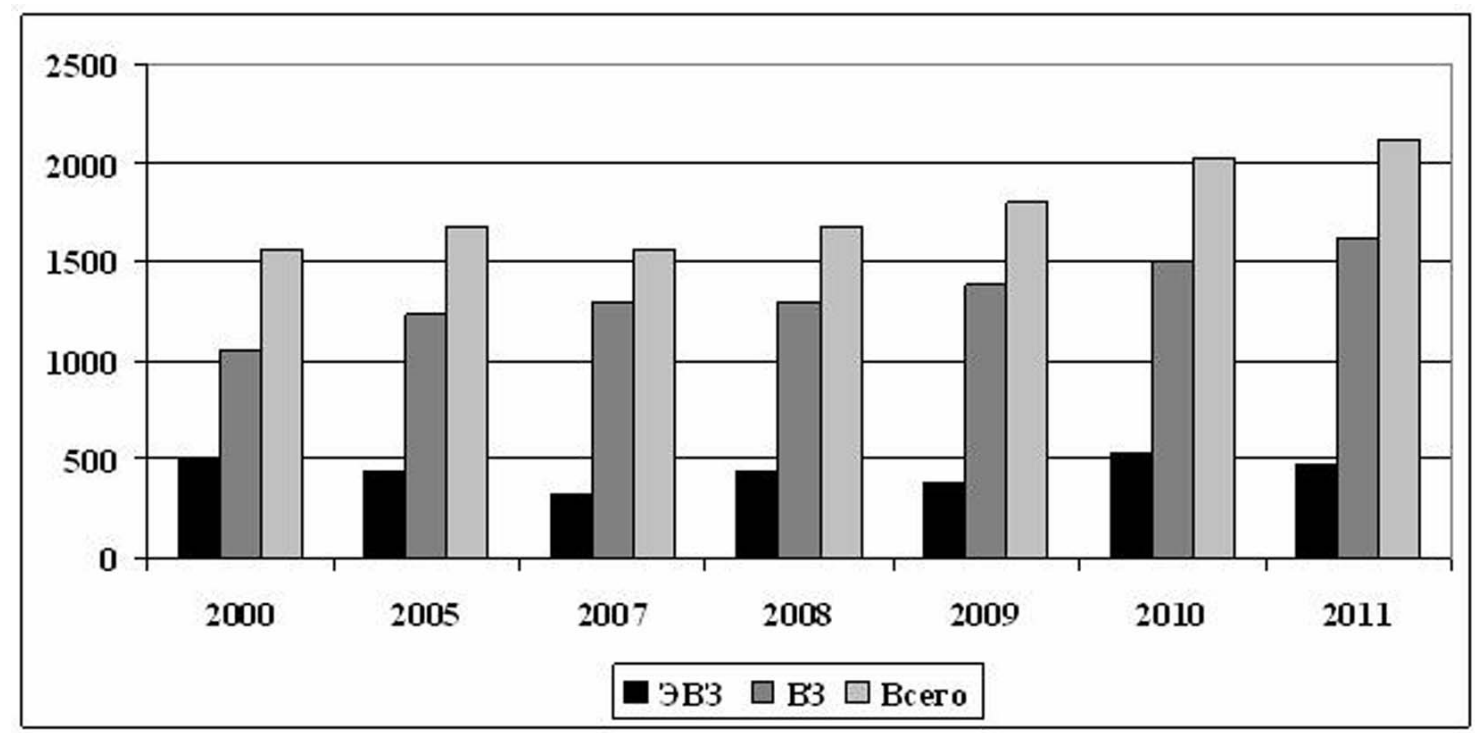

Рисунок 4. Количество случаев экстремально высоких (ЭВ3) и высоких (В3) уровней загрязнения поверхностных и морских вод на территории России [5]

В последние годы м а л о в о д я привлекают к себе меньшее внимание, чем наводнения, в значительной мере из-за общего увеличения водности рек мира, а во многих странах, в т.ч. в России, меженнего стока. Но маловодья и связанная с ними проблема опустынивания остаются актуальными. Один из показателей водообеспеченности населения и хозяйства - удельная (на душу населения) обеспеченность ресурсами речного стока.

Соответствующий расчет выполнен авторами для субъектов РФ [3], согласно которому к числу слабо обеспеченных местными водными ресурсами относятся весь равнинный юго-запад европейской части России, а также юг Западной Сибири.

Учет транзитного (притекающего из соседних районов) стока во многих случаях кардинально меняет общую ситуацию (наиболее наглядный пример Астраханская область), хотя очевидной остается проблемность водообеспеченности названных выше районов. Причем в некоторых из них ситуация обостряется, например, в бассейне Дона.

Снижение водообеспеченности населения наблюдается во многих районах мира, особенно в Азии и Африке. Это связано с ростом численности населения, развитием водоемких отраслей хозяйства, особенно орошаемого земледелия.

В целом водозабор в мире растет, превысив в 2010 г. на 11 с лишним процентов водозабор в 1990 г. При этом в России и ряде сопредельных государств, а также наиболее развитых странах мира водопотребление снижается. В первом слчае главным образом из-за кризисных явлений после распада СССР и перестройки экономики, во втором - вследствие развития водосберегающих технологий.

\section{Загрязнение рек и водоемов}

Угрозу водным ресурсам в большинстве регионов мира составляет не столько рост водопотребления, сколько увеличение количества сточных вод, сбрасываемых в реки и водоемы, и все возрастающее количество новых загрязняющих веществ. Кроме того, все большую роль в загрязнении рек и водоемов играет так называемое диффузное загрязнение (вынос с водосборных территорий удобрений, ядохимикатов, различных отходов хозяйственной деятельности). В результате мероприятия по очистке сточных вод часто не справляются с потоком загрязнений, что ведет к качественному истощению водных ресурсов.

Иллюстрацией к сказанному может служить рис. 4 , из которого следует, что в последнее время, несмотря на предпринимаемые меры по борьбе с загрязнением водных объектов, число случаев с высоким уровнем их загрязнения в России растет. Аналогичная ситуация имеет место и в других районах мира. Примеры улучшения качества вод (Великие американские озера, бассейн Рейна и т.д.), к сожалению, не отражают общую тенденцию.

\section{Заключение}

Таким образом, водные проблемы вызываются как природно-климатическими, так и антропогенными факторами. Но если возможность возникновения стихийных бедствий и их точного предсказания пока весьма ограничена, то возможность снижения их негативных последствий во многом зависит от человека (наиболее радикальные мероприятия - создание водохранилищ, обустройство водосборов, своевременное оповещение и эвакуация населения). 


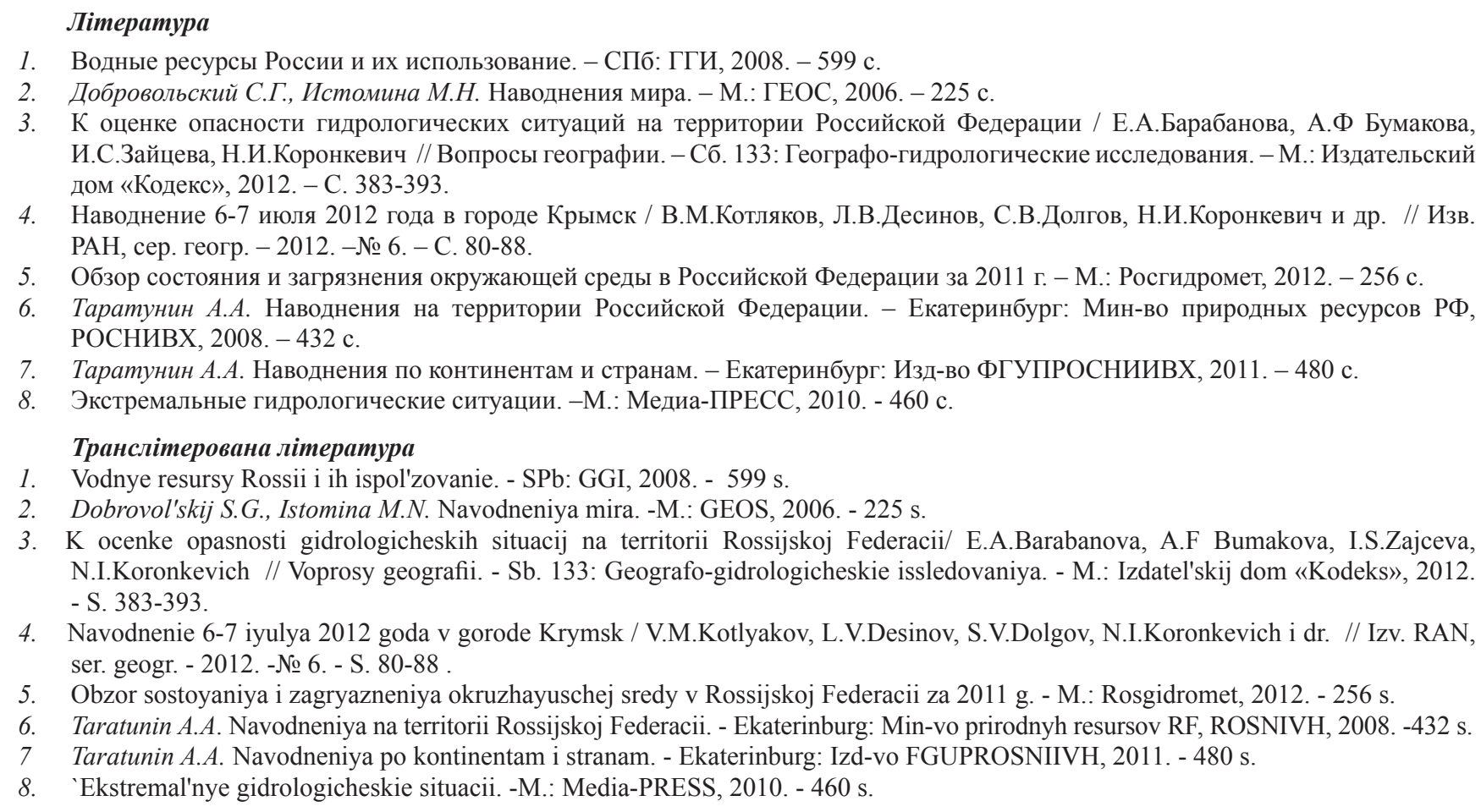

\title{
О.Р. Андріанова \\ ЗМІНИ РІВНЯ СВІТОВОГО ОКЕАНУ В СИСТЕМІ «ОКЕАНОСФЕРА-АТМОСФЕРА- ГІДРОСФЕРА-ПОВЕРХНЯ СУХОДОЛУ॥
}

\begin{abstract}
O.P. Андрианова
ИЗМЕНЕНИЯ УРОВНЯ МИРОВОГО ОКЕАНА В СИСТЕМЕ «ОКЕАНОСФЕРА-АТМОСФЕРА-ГИДРОСФЕРА-ПОВЕРХНОСТЬ СУШИ»

Отделение гидроакустики Морского гидрофизического института Национальной академии наук Украины, Одесса На массовом материале проведен статистический анализ связей между колебаниями уровня Мирового океана (всего 123 станции по побережью каждого океана за 1880-2010 годы) и глобальными фракторами - вариациями угловой скорости Земли, солнечной активностью (числами Вольфа), изменениями термического режима. Расчет их статистических характеристик показал наиболее тесную связь с изменениями глобальной температуры воздуха на Земле по сглаженным 5-летним рядам (коэффициент корреляции 0,94 при сдвиге 18 лет), при запаздывании уровня океана. С вариациями угловой скорости вращения Земли установлена стабильная зависимость с региональными особенностями вдоль побережий океанов величины (месяцев) фразового сдвига коэффициента корреляции. Такие данные важны для климатических оценок и прогнозирования глобальных изменений уровня океана.
\end{abstract}

Ключевые слова: уровень Мирового океана; угловая скорость вращения Земли; температура воздуха; солнечная активность; коэффрициент корреляции.

\section{O. Andrianova}

THE CHANGES OF THE WORLD OCEAN SEA LEVEL IN THE "OCEAN SPHERE-ATMOSPHERE-HYDROSPHERE-LAND SURFACE" SYSTEM

Hydroacoustics department of Marine hydrophysics institute of the National Academy of Sciences of Ukraine, Odesa

The statistical analysis of correlations between fluctuations the World Ocean's sea level (123 stations along the coast of each ocean during 1880-2010) and global factors - variations of the Earth's angular velocity, solar activity (Wolf numbers), and changes in the thermal regime has been analyzed. The calculations of statistical characteristics showed their closest connection with the global temperature changes on the Earth for a 5-year smoothed data (correlation index 0.94 with 18 years shift) and sea level has delayed. The stable connection between variations of the Earth's angular velocity and regional characteristics along the oceans coasts for the magnitude (months) of the correlation index phase shift.

Key words: World Ocean Sea level; Earth's rotation velocity; air temperature; solar activity; the correlation index. 